\title{
O ponto de vista do Interacionismo Sociodiscursivo sobre Saussure
}

\author{
Evandro Gonçalves Leite ${ }^{a}$ \\ Regina Celi Mendes Pereira ${ }^{b}$ \\ Maria do Socorro Maia Fernandes Barbosa ${ }^{c}$
}

\section{Resumo}

Passados cem anos da publicação do Curso de Linguística Geral, os estudos linguísticos têm voltado atenção para a importância e a relativa atualidade do pensamento de Ferdinand de Saussure para a consolidação da linguística como ciência e para disciplinas nesse campo científico. Este trabalho, nessa direção, tem o objetivo de apresentar algumas contribuições do pensamento de Saussure para o Interacionismo Sociodiscursivo, especialmente na explicação do desenvolvimento humano. Consiste numa revisão bibliográfica de textos representativos do Interacionismo Sociodiscursivo que tratam da ressignificação e da integração de teses saussurianas a esse quadro teórico. Os textos apontam que há um processo de (re)descoberta de textos fundamentais de Saussure (manuscritos e notas), que, conjuntamente aos já largamente conhecidos, como o Curso de Linguística Geral, têm provocado reavaliações e ampliações de algumas de suas teses, relacionadas à linguística da fala, à língua como sistema social e, sobretudo, ao signo linguístico, suas características e seu papel no desenvolvimento humano nos planos filogenético e ontogenético.

Palavras-chave: Interacionismo Sociodiscursivo. Saussure. Desenvolvimento humano.

Recebido em 30 de agosto de 2017 Aceito em 02 de janeiro de 2018

\footnotetext{
a Professor de Língua Portuguesa e Literatura do Instituto Federal de Educação, Ciência e Tecnologia do Rio Grande do Norte; E-mail: evandrogleite@yahoo.com.br.

b Professora na graduação e na pós-Graduação em Linguística da UFPB (PROLING/UFPB); E-mail: reginacmps@gmail.com.

c Professora do Departamento de Letras Estrangeiras da UERN; E-mail: socorromaia@uern.br.
} 


\section{Introdução}

No primeiro centenário do Curso de Linguística Geral $(C L G)$, que foi por muito tempo a única fonte propagada sobre o pensamento de Saussure, cresce o interesse pelo mestre genebrino. Por um lado, temos a (re)leitura do próprio CLG, tanto por seu pioneirismo, ao promover uma ruptura epistemológica, lançando as bases do que viria a ser a linguística, quanto pelas repercussões de teses saussurianas em diferentes áreas da linguística contemporânea: estudos enunciativos (SILVA; TITELLO, 2016), funcionalistas (VICENTE; DEFENDI; LIMAHERNANDES, 2016), do discurso (GASPARINI, 2016) e de tradução (SILVA; SEIDEL, 2016), para citar alguns casos. Por outro lado, temos também a (re)descoberta e o estudo de manuscritos que, quando não ampliam as teses do CLG, chegam a negá-las e até pôr em dúvida a fidelidade das ideias contidas no livro ao pensamento saussuriano. Nesse sentido, o interesse por Saussure, na verdade, vem de uma revisão de suas teses e de sua concepção epistemológica, as quais se têm mostrado, em alguns casos, relativamente atuais para algumas correntes dos estudos linguísticos.

Esse empreendimento tem sido realizado pelo Interacionismo Sociodiscursivo (ISD), uma corrente das ciências do humano que investiga principalmente as condições de construção e de funcionamento das capacidades propriamente humanas, com destaque para o agir comunicativo, que tem papel fundador e regulador das atividades e ações sociais. A denominação abrangente de corrente das ciências do humano deve-se, como o próprio Bronckart (1999) ressalta, ao fato de privilegiar uma abordagem interdisciplinar, congregando contribuições da filosofia, da sociologia, da psicologia e da linguística e integrando-as na composição de um quadro teórico.

No caso específico deste artigo, abordaremos as contribuições dos estudos linguísticos de Saussure para o quadro teórico do ISD, principalmente quanto ao papel do signo na constituição e no funcionamento do pensamento consciente, mas também quanto à compatibilidade de outras ideias reveladas pelos manuscritos com teses que alicerçam o ISD. Dada a natureza interdisciplinar desse quadro teórico, “[...] que não aborda os fatos [de linguagem] de maneira 
departamentalizada, mas atravessados e sob a dependência dos diversos saberes [...]" (BASÍLIO; PEREIRA; MENEZES, 2016, p. 418), essas contribuições estão imbricadas às de outras disciplinas e teóricos, especialmente Habermas e Vygotsky. Desse modo, no decorrer do artigo, também buscaremos estabelecer tais relações, sempre que pertinentes.

Assim sendo, nosso trabalho fundamenta-se na leitura de textos basilares do ISD e consiste numa revisão bibliográfica acerca da recepção e da apropriação dos estudos saussurianos nesse campo teórico. Nosso recorte inicia-se por Bronckart (1999), obra que, para o próprio autor, representa um projeto nascente de desenvolvimento de um quadro teórico mais completo no âmbito do interacionismo social e que, com poucas variações, serve de referência até hoje para os estudos do ISD; e estende-se a outras igualmente representativas: de sua autoria - Bronckart (2006a, 2006b, 2007, 2008) - e em parceria com colaboradores - Bronckart e Bulea (2011) e Bronckart, Bulea e Bota (2014).

Otrabalho estrutura-se da seguinte forma: primeiramente, fazemos algumas considerações sobre a recepção dos estudos de Saussure, especialmente no ISD; em seguida, expomos as teses saussurianas assumidas e/ou ressignificadas no campo interacionista sociodiscursivo; logo após, mostramos como essas teses, integradas ao quadro teórico bronckartiano, ajudam a explicar os processos filogenético e ontogenético de desenvolvimento humano; por fim, apresentamos nossas considerações finais.

\section{A recepção dos estudos de Saussure}

É fato que a obra de Saussure mais conhecida e divulgada na academia tem sido o Curso de Linguística Geral, tradicionalmente atribuído a ele, porém editado/organizado por Charles Bally e Albert Sechehaye. Com a renovação do interesse por Saussure e a redescoberta de escritos (notas e manuscritos) não publicados pelo autor, não só a autoria do CLG voltou a ser mais intensamente problematizada, mas também, e principalmente, a própria fidelidade das ideias ali contidas ao pensamento dele. Esse retorno a Saussure e a seus textos tem sido feito sob diferentes perspectivas, que tentaremos resumir brevemente. 
Uma delas pode ser representada por Bouquet $(1999,2014)$, que define dois paradigmas editoriais a guiarem a apreensão do pensamento saussuriano. O primeiro tem como eixo central o CLG, tal como editado por Bally e Sechehaye, os quais não participaram dos cursos ministrados na Universidade de Genebra. O CLG, para Bouquet (2014), é, na verdade, uma obra falsamente atribuída a Saussure - portanto apócrifa - e, o que nos parece mais importante, chegando a desfigurar o pensamento dele em pontos essenciais, como a linguística da fala e sua relação com o sistema (a língua) e o signo e suas propriedades, temas que detalharemos mais adiante. Teríamos, nesse caso, um "Pseudossaussure", cuja proeminência impediu, por muito tempo, que se conhecessem e compreendessem as verdadeiras teses do autor. $\mathrm{O}$ segundo paradigma ganha força com estudiosos de textos originais de Saussure (notas e manuscritos), além de cadernos de anotações de alunos baseadas em lições orais de Saussure. Esses estudiosos defendem que esses escritos ditos autênticos, em alguns casos, se afastam do CLG ou contrariam e ampliam as teses lá contidas. Como exemplos, Bouquet (2014) cita panoramicamente que os escritos dão destaque tanto à linguística da língua quanto à da fala; que termos e ideias desses escritos foram quase ou totalmente suprimidos no CLG, como a palavra "discurso" na acepção de "fala" e também passagens das aulas que tratam do discurso; que foram deturpadas no CLG ideias relacionadas à arbitrariedade do signo. Assim sendo, a investigação dos textos originais amplia o escopo dos estudos saussurianos e apresenta, na visão do autor, o "verdadeiro" Saussure.

Outra perspectiva, que se intitula menos radical em relação a críticas ao $C L G$, pode ser exemplificada pelos trabalhos de Trabant (2005), Castro (2016) e Cruz (2016). Os três reconhecem o caráter de organização/reconstrução que está na gênese da obra, mas comungam da tese de que o CLG é uma fonte legítima do pensamento de Saussure, de modo que as notas e os manuscritos, longe de invalidaremno, são, na verdade, complementares e até dependentes dele. Nessa perspectiva, os escritos ditos autênticos devem ser lidos e interpretados em conexão com o CLG, evidenciando a legitimidade e a coerência do trabalho de Bally e Sechehaye. Nessa mesma linha, Faraco (2016) apresenta três diferentes atitudes de recepção sobre Saussure e seus textos: a primeira 
e a segunda são motivadas pela produção e publicação do CLG, recepção que, num primeiro momento, foi negativa e limitada, sem muita discussão sobre o livro e suas ideias, mas que, posteriormente, provocou o que o autor denomina "efeito Saussure", quando a obra tornou-se a base para desdobramentos que culminaram no estruturalismo linguístico e em influências para diversos campos das ciências humanas e sociais. A terceira atitude é influenciada pela descoberta e publicação de manuscritos e notas de Saussure, seja para descobrir o "verdadeiro" Saussure, seja para encontrar um ponto de equilíbrio entre o CLG e os manuscritos, os quais, na opinião de Faraco (2016), não são tão divergentes.

Como vemos, independentemente da posição que se assuma, a descoberta e a publicação de notas e manuscritos tiveram deveras influência sobre o estudo e as intepretações do pensamento de Saussure, seja para validar, seja para questionar o CLG, configurando, assim, dois momentos de recepção. Ao analisarmos o percurso do ISD quanto à adesão a princípios saussurianos, podemos também perceber esses dois momentos.

O primeiro também está relacionado à proeminência do CLG, tal qual figura em Bronckart (1999). Nesse momento, a referência a Saussure e a seu pensamento, já considerado valioso para o quadro teórico que se vem desenhando, é totalmente subordinada ao CLG, enfatizando as teses, até hoje válidas, sobre o signo e seu papel no desenvolvimento do pensamento consciente, mas sempre no âmbito do sistema da língua. Tanto que, em várias passagens, ele faz ressalvas de que o modelo do signo de Saussure, em que pese sua importância, deve ser estudado para além do sistema posto no CLG, no qual teria sua existência como "constructo abstrato", mas seria secundário em relação às atividades de linguagem. Bronckart (1999) também amplia a noção de língua social de Saussure, por sua visão homogênea do social, de modo que concede pouca importância à língua como sistema, ao considerá-lo como de dimensão inferior e "resíduo estrutural" de uma abordagem descendente (dos textos aos morfemas).

O segundo momento, já alimentado pelos estudos dos textos originais, promove uma revisão e, ao mesmo tempo, uma ampliação do papel de Saussure no âmbito do ISD. O modelo de desenvolvimento de Vygotsky é revisto mediante a função decisiva dos signos, na acepção saussuriana, para o 
${ }^{1}$ Bota e Bronckart (2014, p. 251) chegam a afirmar que o CLG corresponde a uma visão parcial, d e f o r m a d a e "potencialmente e s c le ros a $\mathrm{te}$ " do pensamento saussuriano. Em nossa leitura das contribuições de Sausure para o ISD, entretanto, não chegamos a essa conclusão: percebemos, por exemplo, que a noção de signo é bastante tributária do CLG. desenvolvimento do pensamento consciente tanto na filogênese quanto na ontogênese. Além disso, outras teses revisitadas e reformuladas ganham destaque como compatíveis com o ISD: a ideia do caráter social do sistema da língua (langue) articulado dialeticamente com as atividades de linguagem (parole), dando a esta um destaque não visto no CLG. Nesse segundo momento, o CLG, embora não demonizado, é ampliado, enriquecido e, por vezes, contestado ${ }^{1}$ pelos textos recuperados (BRONCKART; BULEA, 2014). O protagonismo de Saussure no ISD cresce de tal forma que Bronckart (2006b, p. 5) chega a afirmar que Saussure constitui, atualmente, um de seus principais alicerces: “[...] $\mathrm{Na}$ cronologia de nosso percurso, esse autor é, portanto, nossa segunda referência epistemológica maior, mas ele tende, hoje, a tornar-se nossa referência principal, em razão da importância decisiva das perspectivas abertas por seus escritos [...]".

Neste artigo, levamos em consideração justamente o estágio atual do ISD acerca do pensamento saussuriano, apresentando as teses que são revisitadas e incorporadas ao quadro epistemológico dessa corrente interacionista, mediante a descoberta de textos originais que se somam aos já amplamente divulgados e conhecidos ou os reorientam.

\section{Teses de Saussure importantes para o ISD}

Para Bronckart (1999), falar da importância das teses saussurianas para o ISD é também, por extensão, falar de sua importância e de sua relativa atualidade para o interacionismo social em uma acepção mais ampla. $\mathrm{O}$ corpus saussuriano, (para) além do CLG, pode ajudar a explicar a emergência das capacidades propriamente humanas, especialmente o desenvolvimento da linguagem. Três aspectos principais dos estudos saussurianos recebem atenção especial nesse processo: a linguística da fala, a língua como sistema social e a teoria do signo linguístico.

Discorrer sobre a importância da linguística da fala para Saussure é, certamente, ir de encontro ao CLG, o que confere a essa tese uma das maiores redescobertas dos estudos neossaussurianos. Embora o CLG ateste o caráter primário e social da língua e secundário e individual da fala, o estudo de textos ditos autênticos, como Lendas e Escritos de Linguística 
Geral, permite vislumbrar outras concepções mais complexas desses dois fenômenos.

Além do estudo da língua, Saussure propõe, em outros escritos, o estudo de outros aspectos da linguagem, de modo a aplicar a essas outras dimensões (dos textos/discursos) esse procedimento sistêmico. Bota e Bronckart (2014) e Rastier (2014) salientam que boa parte da vida acadêmica de Saussure foi dedicada à investigação dos anagramas e de lendas, o que já amplia seu escopo para além do sistema abstrato da língua.

Sobretudo nas lendas, Saussure procurava relacionar, segundo os autores, estruturas narrativas referentes a normas de composição a substratos históricos, de modo a identificar o valor sócio-histórico das lendas e sua transmissão em outros textos. Estabelecer relação entre as normas sociais e os textos que as constroem e ativam significaria, em termos saussurianos, o primado da fala sobre a língua, ou, como preferem Bota e Bronckart (2014), da atividade social e dos textos sobre os componentes abstratos do sistema. Mais do que isso, permite inferir que subjaz, como bem aponta Bronckart (2014), que o semiótico intermedeia os valores sociais e as representações individuais.

Entretanto, os estudos da fala e da língua não seriam mutuamente excludentes. A esse respeito, Bronckart (2007) esclarece que os escritos de fato saussurianos assumem que a fala seria realmente individual, como ato de um indivíduo, mas nem por isso livre das coerções sociais da coletividade. Mais do que isso, a existência de um sistema seria o produto da fala, ou seja, do uso da linguagem pelos falantes; assim como as mudanças que acontecem no sistema teriam a fala como propulsora. Nas palavras de Bota e Bronckart (2014, p. 236):

Com efeito, o corpus saussuriano abunda em fórmulas que postulam que as significações se constituem no discurso, que é só num segundo momento que elas integram o tesouro mental da língua e ali se reorganizam sob uma outra modalidade, e que a atividade de comparação-classificação decorrente dessa língua é, ela mesma, orientada pelo e para o discurso.

Como vemos, a fala deixa de ser mera manifestação acidental da língua para ser a modalidade que organiza e alimenta o sistema, este visto como depósito passivo enquanto aquela como viva e ativa. $O$ fato de essa noção não ter, segundo 
${ }^{2}$ Posição diferente é defendida por Castro (2016), que vê nesse ponto uma questão complexa que tem suscitado distintas interpretações. Para ele, o CLG não opera uma divisão definitiva entre língua e fala, citando, como exemplo, trecho da introdução do CLG em que se afirma a interdependência entre ambas, que seriam estreitamente ligadas (SAUSSURE, 1972 apud CASTRO, 2016). Entretanto, não deixa de observar também que, em outras passagens do $C L G$, afirma-se a necessidade de escolher uma das vertentes para estudo, a língua, deixando de lado tudo que é estranho ao sistema e a sua ordem ou seja, a linguística externa, do domínio da fala.
Bronckart (2008), integrado o CLG deve-se, na visão dele, aos editores/autores, que a teriam ocultado, ao passo que os manuscritos chegam a usar o termo "discurso" para designar a prática da fala ${ }^{2}$.

Apesar de não ter sido adequadamente desenvolvida nem compreendida pelo próprio Saussure, essa tese do primado da fala (ou discurso) sobre a língua é compatível com as ideias do ISD e também de muitas correntes contemporâneas de estudos linguísticos textuais, discursivos e enunciativos. Especificamente na esteira do ISD, Bronckart (1999, 2006a) privilegia o estudo da linguagem em sua dimensão textual e/ ou discursiva, já que os textos/discursos são as manifestações e, ao mesmo tempo, os organizadores das ações humanas.

Essa visão acerca da linguística da fala reorienta a compreensão que temos da língua como sistema, tal qual posta no CLG. A tese da língua como sistema, por muito tempo predominante ou exclusiva, passa a dividir atenção com a linguística da fala, conforme já apresentamos acima, que, apesar de manter a dicotomia, não relega uma de suas dimensões a segundo plano.

A noção de língua como sistema é evidentemente tributária do CLG, onde foi apresentada e detalhada, e refere-se ao conjunto de relações que existe em potência na consciência dos falantes (SAUSSURE, 2012). Não se trata, nesse caso, da colocação em discurso das formas abstratas, mas do tesouro depositado na consciência dos falantes.

Esse tesouro, como fica claro no CLG e nos escritos recuperados, é social porque compartilhado por uma coletividade. Entretanto, no escopo do ISD, essa noção homogênea do social é revista e ampliada, conforme Bronckart (1999), para dar conta das múltiplas formações sociais que desenvolvem modalidades particulares de funcionamento da língua, as formações sociodiscursivas, que geram modalidades particulares de funcionamento da linguagem: os gêneros de texto. É justamente essa característica da língua, em seu sistema e em seu funcionamento, que permite a intercompreensão entre os membros de uma comunidade, ou seja, entre os falantes de uma língua natural.

Por ser social, a língua é também histórica, como objeto em constante transformação. A esse respeito, Bota e Bronckart (2014) falam de continuidade dos fatos da língua, segundo a qual a 
linguagem é uma entidade una, mas de estágios sucessivos, sem que haja, na verdade, uma ruptura radical do sistema quando considerado em sua condição sincrônica ou na percepção dos falantes de uma comunidade. Essa é uma noção que advém dos manuscritos, que conferem dinamicidade ao sistema.

A dimensão social e histórica da língua alça-a, para Saussure, à condição de instituição social fundadora e organizadora das demais, mas não numa relação de reciprocidade. Por esse motivo, Bota e Bronckart (2014) acreditam que ele deixou de dar destaque a fenômenos relacionados ao discurso, como a criação das significações, que se dão nas e pelas práticas sociais de interação verbal. Além disso, ressaltam também que Saussure, nos cursos que culminaram no $C L G$, optou por privilegiar a língua sistêmica e sincrônica. Desse modo, a abordagem de aspectos relacionados ao discurso (à fala) em partes de sua obra não recebeu o aprofundamento e o destaque necessários.

Essa noção de sistema tem sua importância para o ISD. Embora considere os textos/discursos como as manifestações empíricas e, portanto, as unidades concretas das ações humanas, o ISD não nega a existência de um sistema, como um constructo abstrato, pois as ações de linguagem se realizam numa língua natural: "[...] toda língua natural apresenta-se como estando baseada em um código ou um sistema, composto de regras fonológicas, lexicais e sintáticas relativamente estáveis, que possibilita a intercompreensão no seio de uma comunidade verbal. [...]" (BRONCKART, 1999, p. 69, grifo do autor).

As operações de linguagem que Bronckart (1999) procura caracterizar se manifestam, portanto, numa língua natural. Assim, os conhecimentos que permitem a um agente interpretar ou produzir um texto estão certamente no plano acional, nas práticas sociais em interface com a linguagem e os gêneros de texto, mas também no plano das regras do sistema de uma língua natural. Um texto empírico, desse modo, é o resultado da colocação em funcionamento de representações sobre o contexto situacional, os gêneros de texto e a língua, todas imbricadas. Entretanto, apesar de defender que há, deveras, componentes estruturais no plano da língua na constituição dos textos, Bronckart (2006a) nega que estes sejam unidades linguísticas. No quadro do ISD, os textos são unidades comunicativas, pois suas condições de produção e 
de funcionamento são dadas pela ação de linguagem da qual eles são os correspondentes empíricos: "Chamamos de texto toda unidade de produção de linguagem situada, acabada e autossuficiente (do ponto de vista da ação e da comunicação). [...]" (BRONCKART, 1999, p. 75, grifo do autor).

Esse estatuto essencialmente comunicativo e pragmático da linguagem reforça, por sua vez, as considerações sobre a linguística da fala. Se a linguagem funciona e se organiza através dos textos que materializam as ações de linguagem no âmbito das atividades linguageiras que constituem, organizam e permeiam o ser e o fazer humanos, o ISD assume, como síntese entre seus postulados centrais e as contribuições saussurianas, que a língua é apreendida através dos textos, que são primeiros, enquanto o sistema é secundário, um produto da apropriação do valor dos signos veiculados na fala. Essa conclusão, aparentemente óbvia, coloca como desafio para o ISD a necessidade de estabelecer tal relação, de modo a integrar o estudo dos textos/discursos ao sistema da língua.

A terceira tese saussuriana adotada pelo ISD é em relação ao signo linguístico e suas características. Essa é, sem dúvida, a noção mais evocada nos textos de Bronckart, pois ajuda a explicar a apropriação da linguagem pelos seres humanos tanto numa perspectiva filogenética quanto ontogenética, como veremos mais à frente.

O signo linguístico, tal como caracterizado no CLG e nos manuscritos saussurianos, pode ser definido como a unidade que, em conjunto, forma o sistema da língua. Trata-se de uma entidade psico-mental, formada pelo acoplamento de dois domínios: significante e significado, que correspondem, respectivamente, à imagem acústica como representação psíquica de um som e à significação que ela evoca.

Além disso, o signo possui algumas características que são basilares: é imotivado, arbitrário, discreto, não substancial, processual e de valor relacional e opositivo. É imotivado porque não há relação natural entre o signo e o seu referente, pois ela deriva de acordos sociais. É arbitrário, ou radicalmente arbitrário, porque não há relação natural entre o significante e o significado. É discreto porque cada signo transforma o pensamento como massa amorfa em unidades desdobradas que permitem a tomada de consciência do indivíduo e a representação do mundo pelos signos. É não substancial 
porque os signos, de natureza convencional e não natural, são como envelopes vazios aptos a receber qualquer significação, de acordo com o agir comunicativo de uma coletividade. É processual porque, sendo o acoplamento de significante e significado puramente relacional e convencional, está sujeito a mudanças, de modo que há nos signos que compõem uma língua uma atividade incessante de (re)produção de linguagem, tendo em vista a necessidade de entendimento entre os interlocutores. Finalmente, possui valor relacional e opositivo porque o signo, nas relações in absentia entre seu significante e significado e com os demais e na relação in praesentia na sintagmação do signo, só existe e se diferencia por oposição no interior do sistema que integra (BOUQUET, 2014). Portanto, os signos, como apontam Bronckart e Bulea (2011), são fenômenos complexos: definem-se em relação aos outros, de forma negativa e pela associação entre forma e sentido, tudo no interior da ordem semiótica.

Duas conclusões importantes para o ISD podem ser depreendidas da noção saussuriana de signo linguístico.

A primeira diz respeito à essência social dos signos como entidades coletivas negociadas socialmente e sujeitas a mudanças. O signo se estabiliza nas negociações sociais, nas atividades de linguagem, por sua natureza convencional, de modo que são dependentes do uso: "Portanto, o valor ou o significado de um signo é o produto de acordos sociais (relativamente) estabilizados e organizados em sistema. $\mathrm{O}$ signo e seu valor são, assim, em si mesmos ou em essência, de natureza fundamentalmente social, interativa" (BRONCKART, 2007, p. 29-30). São sociais o nascimento e o desenvolvimento, bem como as mudanças no signo, que se operam na coletividade. Para o ISD, isso significa que sua existência e sua utilização pelos falantes estão indexadas ao gênero de texto e ao contexto ao qual pertence.

A segunda diz respeito à noção de semiotização do pensamento. Conforme Bronckart e Bulea (2011), as características dos signos atestam o caráter essencialmente semiótico das significações, uma vez que elas não se condicionam pelas propriedades dos referentes do mundo nem preexistem à língua. Assim, não haveria um pensamento puro independente dos signos e preexistente à língua, conforme se apresenta no próprio CLG. Dessa forma, a natureza do signo 
ajuda a lançar luz sobre a relação entre a linguagem, as línguas e o pensamento humano, conforme mostraremos mais à frente.

Portanto, como síntese das ideias de Saussure que são (parcialmente) aceitas e/ou reformuladas no quadro do ISD, podemos mencionar a realocação do lugar da linguística da língua e da linguística da fala no escopo do pensamento saussuriano; a língua como sistema e instituição social, articulada com as atividades humanas, e também como uso, o qual alimenta o funcionamento e a dinâmica do sistema; a semiotização do pensamento, tendo o signo como unidade linguística cuja aquisição transforma a massa amorfa e indistinta do pensamento em consciência.

Nas próximas seções, veremos como essas teses se integram ao campo teórico interdisciplinar do ISD para explicar a evolução filogenética e ontogenética do pensamento consciente nos seres humanos, bem como o papel do agir linguageiro nesses processos.

\section{As teses de Saussure na explicação da filogênese}

Como já exposto acima, uma das tarefas do interacionismo social, que o ISD também toma para si, é de explicar as condições de emergência e de funcionamento das chamadas funções psicológicas superiores dos indivíduos e a relação delas com o social, com o mundo tal qual os indivíduos o representam. É nesse sentido que Bronckart (1999) e obras posteriores colocam como um dos alicerces principais de sua teoria o pensamento de Vygotsky, que integra a psicologia com uma abordagem de cunho histórico-cultural.

Vygotsky (2007) fala de duas dimensões do desenvolvimento das funções psicológicas superiores nos seres humanos: uma filogenética, que dá conta do processo de evolução da espécie humana, dos primatas aos hominídeos, e da aquisição do pensamento consciente e da linguagem, ambos integrados; e outra ontogenética, que dá conta da aquisição dessas funções

${ }^{3}$ Bronckart (2006a) chega a afirmar que a noção de signo de Saussure se assemelha à visão vygotskiana de palavra, a qual seria responsável pelo desenvolvimento humano nos planos fi logenético e ontogenético. pela criança, em interação com os demais seres da espécie. Em ambos os processos de desenvolvimento, a linguagem tem um papel decisivo. O que faz o ISD (Cf. BRONCKART, 1999) é integrar as teses vygotskianas com as de outros autores, e em especial com as de Saussure sobre a natureza do signo ${ }^{3}$, relação ainda mais aprofundada a partir de Bronckart (2006a), quando 
as teses vygotskianas são revistas e melhor explicadas graças às contribuições dos estudos de/sobre Saussure.

Quanto a esse aspecto, a nova dimensão que os escritos saussurianos dão à fala parece decisiva para que o ISD assuma mais claramente o papel do signo para o desenvolvimento humano, já que integrado ao uso linguístico, de modo que a fala não é estranha ao sistema, aos seus componentes e ao seu funcionamento, mas exatamente a instância que o alimenta. Se, como já apontamos mais acima, as significações se constroem no discurso, o signo, por extensão, tem igual constituição, ou seja, seu valor é social, interativo e movente, advindo do agir comunicativo, já que a fala é a fonte de criação e de modificação de novas formas da língua. De igual modo, a apropriação do signo se dá na fala (no discurso), já que, na proposta do ISD, os textos são primeiros e fundam a possibilidade de comunicação, como manifestações do agir linguageiro. Para comprovar essa afirmação, Bronckart (2006a, 2007, 2014) e Rastier (2014) mencionam trechos dos Escritos de Linguística Geral e de notas dos alunos, alguns dos quais reproduzimos para efeito de exemplificação:

A linguística, ouso dizer, é vasta. Principalmente, ela comporta duas partes: uma está mais perto da língua, depósito passivo, a outra que é mais perto da fala, força ativa e origem verdadeira dos fenômenos que se percebem, em seguida, na outra metade da linguagem. (SAUSSURE, 2002 apud RASTIER, 2014, p. 382, grifo do autor)

Todas as modificações, sejam fonéticas, sejam gramaticais (analógicas) se fazem exclusivamente no discursivo [...] Toda inovação chega por improvisação, falando-se, e penetra por aí no tesouro íntimo do ouvinte ou do orador, mas se produz a propósito do discursivo. (SAUSSURE, 2002 apud BRONCKART, 2006a, p. 110)

O valor de uma forma está por inteiro no texto em que a colhemos. (BALLY; GAUTIER, 1984 apud BRONCKART, 2014, p. 409)

Assim, a concepção de signo com a qual opera o ISD é, evidentemente, tributária do CLG, mas ganha contornos advindos de diferentes trabalhos interpretativos sobre Saussure. O signo, nesse caso, integra um sistema que se relaciona dialeticamente com a fala, ou, como prefere o ISD, 
com o agir linguageiro, e passa a ser central na explicação do desenvolvimento humano, na emergência do pensamento consciente e na construção e representação do mundo.

Embora o desenvolvimento filogenético não seja o foco principal do ISD, ele é abordado em Bronckart (1999, 2006a), já que tem o agir de linguagem como seu principal desencadeador e, consequentemente, como principal traço caracterizador do humano. Segundo Bronckart (1999), na espécie humana, as atividades sociais são mais complexas e organizadas do que as das demais espécies animais. Nestas, as atividades estão ligadas à sobrevivência e não se distanciam do meio prático onde ocorrem; portanto, são idiossincráticas, não negociadas. Naquela, porém, as atividades sociais, integradas à emergência da linguagem, veiculam representações negociadas sobre o meio, que nos permitem agir nele e sobre ele.

Para Bronckart (2006a), antes do desenvolvimento do agir comunicacional propriamente dito, os hominídeos, assim como as outras espécies animais, usavam "sinais desencadeadores" para se comunicar com outros membros da espécie, mas nunca se distanciando do meio, sendo estes sinais também representações idiossincráticas. Entre outros desenvolvimentos biocomportamentais, o homo sapiens desenvolveu sinais convencionados socialmente para entrar em acordo com os demais membros da espécie. Desse agir comunicativo negociado que se fundou na relação entre sequências de sons e ideias para representar o meio, teriam surgido os signos linguísticos, com suas propriedades, e as línguas naturais. Nas palavras de Bronckart (1999, p. 33):

[...] A linguagem propriamente dita teria então emergido, sob o efeito de uma negociação prática (ou inconsciente) das pretensões à validade designativa das produções sonoras dos membros de um grupo envolvidos em uma mesma atividade. Portanto, seria na cooperação ativa que se estabilizariam as relações designativas, como formas comuns de correspondência entre representações sonoras e representações sobre quaisquer aspectos do meio, isto é, como signos, na acepção saussureana mais profunda do termo. Signos que, pelo seu próprio estatuto de formas oriundas de uma negociação, teriam necessariamente reestruturado as representações dos indivíduos, até então idiossincráticas, e as teriam transformado em representações pelo menos parcialmente comuns, compartilháveis, ou ainda comunicáveis. (Grifo do autor) 
Existem três consequências principais relacionadas ao surgimento e à prática dos signos: a emergência da atividade de linguagem; a constituição dos mundos formais de conhecimento; e a transformação do psiquismo primário em pensamento consciente (este no plano ontogenético).

A linguagem é, antes de tudo, uma atividade social humana com função pragmática e comunicativa. É no uso que surgem e se estabilizam os signos, como sinais convencionais com vistas à intercompreensão humana. Bronckart (1999, p. 34-35) atesta que:

[...] A linguagem é, primariamente, uma característica da atividade social humana, cuja função maior é de ordem comunicativa ou pragmática. É só sob o efeito da confrontação do valor ilocutório das produções dos interactantes que se estabilizam progressivamente os signos, como formas compartilhadas (ou convencionais) de correspondência entre representações sonoras e representações de entidades do mundo. Cada signo veiculando, desse modo, um determinado significado (conjunto de representações particulares compreendidas em um significante coletivo), a linguagem se encontra então dotada de uma outra função, que é da ordem do representativo ou do declarativo. (Grifo do autor)

Como vemos, é a semiotização das relações com o meio que transforma as representações idiossincráticas dos organismos humanos em sociais; é também ela que passa a controlar essas representações, que se autonomizam e se distanciam desse meio. Esse fenômeno dá origem a uma atividade social específica, a atividade de linguagem, que se organiza em discursos ou textos, as unidades comunicativas empíricas do agir linguageiro. Uma vez que as atividades sociais de linguagem se desenvolvem e se diversificam, surgem, atrelados a elas, os gêneros de texto, como espécies de textos que estão articuladas às formações sociais no quadro das quais são produzidos.

Entretanto, além dessas, há uma função secundária, representativa ou declarativa, que se refere à construção de conhecimentos sobre o mundo. Esta é a segunda consequência da prática dos signos: a constituição de representações coletivas sobre o meio, que se estruturam em mundos representados.

[...] Com a emergência dos signos, a prática de linguagem se encontra dotada de uma função secundária, com caráter de locutório ou declarativo: largas camadas dos mundos 
representados se encontram recodificadas nos signos e nos sistemas particulares que as organizam; o sujeito interioriza esse conhecimento verbal, que constitui, enquanto tal, um filtro de seu acesso ao mundo. (BRONCKART, 2006a, p. 76, grifo do autor)

Assim, a prática dos signos (ou agir comunicativo) transforma o meio em mundos representados, que constituem o contexto das atividades humanas. Os signos, nesse caso, permitem o estabelecimento de correspondência entre produções sonoras e representações do mundo e são, por isso, constitutivos do social e dos conhecimentos humanos como construto coletivo (Cf. BRONCKART, 1999).

Unindo a abordagem do psiquismo social e do signo saussuriano com a teoria do agir linguageiro de base habermasiana, Bronckart (1999) postula a racionalidade como social e interiorizada, uma vez que os signos organizam as representações humanas, pois constroem os mundos objetivo, social e subjetivo que guiam o agir humano. Do ponto de vista da ação de linguagem, as representações sobre os mundos atuam como balizadoras da avaliação dos seres humanos sobre as ações dos outros (estatuto externo da ação) e também como conjunto de conhecimentos que são apropriados e postos em prática por um agente singular no curso de suas ações (estatuto interno da ação). Desse modo, na realização de uma ação de linguagem, os conhecimentos apropriados por um agente sobre os mundos representados (objetivo, social e subjetivo) são semantizados pelos signos como referentes (conteúdo temático) ou mobilizados como controle do processo de semiotização e de seleção dos signos entre as possibilidades de uma língua, processo traduzido em texto empírico.

São esses mundos representados construídos pelos signos em uso que explicam, inclusive, a existência de culturas diferentes. Segundo Bronckart (1999), como são os signos e os textos, sempre moventes, que constroem os mundos definidores do contexto das atividades sociais humanas, esses mundos também se transformam continuamente. Cada língua, com seus signos, difere de outras, tendo uma semântica própria que atua na construção dos mundos representados, cuja diversidade em termos de semiotização reflete-se em variações entre culturas humanas. "[...] Portanto, o desenvolvimento dos conhecimentos humanos apresenta-se como um processo 
contínuo de confrontar e de negociar o valor atribuído a um signo por uma pessoa individual com os valores atribuídos a esse mesmo signo nos diferentes pré-construídos coletivos" (BRONCKART, 2006a, p. 250, grifo do autor).

A terceira e principal consequência para o ISD, que remete ao desenvolvimento do pensamento consciente numa perspectiva ontogenética, será abordada na seção seguinte.

\section{As teses de Saussure na explicação da ontogênese}

O estudo da emergência ontogenética das capacidades humanas e do papel da socialização e da linguagem nesse processo é uma das principais tarefas e preocupações do ISD. Também é esse o campo em que as contribuições de Saussure parecem mais decisivas. Se, num primeiro momento, Bronckart (1999) adere quase incondicionalmente às teses vygotskianas do desenvolvimento das capacidades humanas e de interiorização da linguagem pelas crianças, num segundo (Cf. BRONCKART, 2006a, 2014; BRONCKART; BULEA, 2011), algumas questões do modelo vygotskiano são revistas, enriquecidas e até "validadas" pelas contribuições dos estudos saussurianos.

É certo que algumas teses vygotskianas são preservadas. Bronckart e Bulea (2011) aceitam o caráter decisivo da apropriação da linguagem para a transformação do psiquismo primário em pensamento consciente; a existência de uma unidade de pensamento verbal, de caráter psíquico, dinâmico, processual e complexo; e, sobretudo, a essência do esquema desenvolvimental vygotskiano:

[... 1) o jovem humano é dotado de um equipamento biocomportamental e psíquico inicial, que, enquanto procede da evolução contínua das espécies, o dote de potencialidades novas; 2) desde o nascimento, o jovem humano é mergulhado em um mundo de pré-construtos sócio-históricos: formas de atividade, coletivas, obras e fatos culturais, produções semióticas que emergem de uma língua natural dada, etc.; 3) desde o nascimento, ainda, o ambiente humano empreende caminhadas deliberadas de formação, que visam integrar o jovem humano nessas redes de pré-construtos, ou que guiam sua apropriação destes últimos; 4) no quadro desse processo de apropriação, a criança interioriza propriedades da atividade coletiva assim como signos e estruturas de linguagem que a mediatizam; 5) essa interiorização das estruturas e significações sociais 
transforma radicalmente o psiquismo herdado e dá origem às capacidades do pensamento consciente. Nessa perspectiva, é, então, a integração de elementos semióticos e sociais que é constitutiva do pensamento propriamente humano. (BRONCKART, 2006b, p. 5)

Outras teses, porém, são rejeitadas ou revistas: as duas raízes disjuntas do pensamento e da linguagem, postulando a existência de um pensamento puro (pré-verbal) universal e de uma linguagem pré-intelectual, que num certo momento se cruzariam; problemas terminológicos relacionados aos termos "pensamento" e "linguagem"; e a falta de clareza quanto ao papel das instituições sociais e dos signos/significações na emergência do pensamento consciente e na transformação deste em sócio-histórico. É justamente sobre essas lacunas ou pontos criticáveis que incidem as contribuições saussurianas, que apresentaremos a partir de agora.

O primeiro ponto, das raízes disjuntas do pensamento e da linguagem, é criticado em virtude da defesa do ISD de que a semiose é primeira e, consequentemente, fundadora do pensamento consciente. Para tanto, Bronckart (2006a) busca respaldo na concepção de signo como fato psico-mental; na negação de um pensamento puro, anterior ou independente dos signos e de sua apropriação, já que não passaria de uma massa amorfa e indistinta; e na definição de uma unidade de análise das ciências humanas e sociais e compreensão de suas dimensões físicas e psíquicas (o signo saussuriano em correlação com a palavra vygotskiana). Desse modo, a compreensão do signo como entidade coletiva, criadora das representações humanas sobre o mundo e, portanto, fundadora da consciência, não permitiria aderir à ideia de um pensamento pré-verbal, que, só posteriormente, num processo de socialização e de interiorização da palavra, se cruzaria com uma linguagem até aquele momento pré-intelectual. Sendo assim, a concepção saussuriana do signo e suas propriedades reforça a primazia do agir linguageiro no processo de desenvolvimento das capacidades humanas.

O segundo ponto refere-se à oscilação terminológica de conceitos como "pensamento" e "linguagem" na teoria vygotskiana. Bronckart e Bulea (2011) afirmam que Vygotsky usa a expressão "pensamento" para designar tanto a inteligência prática quanto o pensamento consciente, ou verbal. Do mesmo 
modo, usa a expressão "linguagem" ora em sentido mais genérico de comunicação, ora para designar a fala ou a palavra. Enquanto esses autores partem desse dado para corroborar a crítica à disjunção entre pensamento e linguagem, ainda somada à fluidez terminológica, Matencio (2007) usa-o para defender que Vygotsky, na verdade, não opera uma disjunção entre pensamento e linguagem, mas entre pensamento e palavra (ou signo), de modo que, na visão da autora, não haveria divergências entre o modelo desenvolvimental de Vygotsky e o do ISD quanto a esse aspecto. Entretanto, a autora não deixa de apontar tal oscilação, atribuindo-a a problemas de tradução e mesmo à imprecisão de conceitos que, à época, eram mal delimitados inclusive no campo da linguística.

O terceiro ponto diz respeito justamente ao papel dos signos nesse processo de desenvolvimento. Segundo Bronckart (2006a), a criança, ao nascer, apresenta capacidades psíquicas herdadas, relacionadas à inteligência prática, que não ultrapassam o meio e não se refletem numa ação sobre a qual ela tenha consciência. A passagem/transformação dessa fase para o pensamento consciente dá-se mediante a apropriação dos signos e de seus usos numa língua natural. Nesse aspecto, a contribuição de Saussure é decisiva para explicar essa transformação do desenvolvimento biológico para o sócio-histórico, justamente pelas características sociais dos signos e da linguagem:

[...] Por seu caráter imotivado (sua ausência de fundamento natural), os signos conferem ao funcionamento psíquico uma autonomia real no que concerne às condições de reforço do meio, autonomia que é uma condição para o estabelecimento de representações permanentes. Por seu caráter discreto, os signos introduzem delimitações, recortes no funcionamento representativo, em outros termos, eles aí estabilizam unidades, o que constitui uma condição para que se possa instaurar um sistema de operações ou de pensamento. Finalmente, por seu caráter radicalmente arbitrário, enfim, os signos provocam um desdobramento do funcionamento psíquico; eles introduzem, sobre as imagens mentais idiossincráticas que todo organismo é suscetível de construir em suas interações com o meio, tipos de envelopes sociais que reagrupam e reanalisam essas mesmas imagens primárias, desdobramento gerador de uma possibilidade de se porem em relação essas duas ordens de representações, 
o que parece constituir uma condição de acessibilidade do pensamento a ele mesmo, ou seja, da emergência da consciência". (BRONCKART, 2006a, p. 113-114, grifo do autor)

Os signos são, desse modo, unidades complexas de representação e, por isso, instrumentos que regulam as atividades sociais, já que constroem e organizam nossas intervenções no mundo e sobre outros sujeitos. Desse modo, ao interiorizar os signos, a criança não só age sobre o mundo e sobre os outros indivíduos, mas também sobre si mesma, sobre suas ações imersas nas atividades coletivas, tornando-se o psiquismo autorreflexivo.

As propriedades dos signos reforçam, além disso, o papel fundamental do social e das interações com outros sujeitos no processo de interiorização da linguagem e de construção do pensamento. Uma vez que os signos não são correspondências naturais entre objetos/comportamentos e produções sonoras, mas frutos de incessantes e por vezes moventes negociações sociais, a criança, sozinha e isolada das interações, não se apropriaria deles. Do mesmo modo, é esse processo de aprendizagem dos signos e seus valores sociais que determina o desenvolvimento da criança, e não o contrário.

Com base em Bronckart (2006a), podemos então definir o percurso de interiorização, pelas crianças, das unidades de linguagem, quais sejam: os signos e, como acrescenta Bronckart (2014), as relações sintagmáticas e predicativas atestáveis no discurso. Desde o nascimento, a criança é confrontada com o mundo físico, de objetos, mas também com o mundo social, cujas relações são mediadas pela linguagem, através das intervenções humanas para integrá-la nesse ambiente. Mediante capacidades inatas como assimilação, acomodação e regulação, ela vai criando traços representativos práticos e não conscientes dos parâmetros e dos objetos implicados nas atividades humanas, parâmetros que são, nessa fase, ainda indistintos em relação aos três mundos (objetivo, social e subjetivo) que constroem o contexto das atividades e idiossincráticos, porque partem somente do seu mundo vivido e não das regulações provenientes das atividades e ações dos outros humanos. Concomitantemente, vai internalizando traços representativos práticos do agir de linguagem e sua função ilocutória, num primeiro momento, que permitem à 
criança utilizar produções vocais no âmbito do seu mundo vivido. Num segundo momento, esses traços representativos práticos do agir comunicacional ganham também uma função locutória, quando estabelece correspondência entre unidades sonoras e ações e objetos com os quais se confronta em seu meio, apreendendo o estatuto prático dos signos, e, mais adiante, quando é capaz de organizar e reconfigurar suas ações em produções verbais que lhe permitem agir no e sobre $o$ mundo. Assim, a apreensão da função locutória da linguagem transforma as capacidades representativas da criança, que passa a organizar suas ações e representações em unidades discretas mais estáveis, utilizar as unidades sonoras para organizar suas representações e conhecimentos do mundo, negociando-os e ajustando-os aos do mundo dos adultos.

Interessante notar que o processo de constituição dos signos envolve processos de assimilação, acomodação, associação e diferenciação que estão na base de processos psíquicos nas espécies animais, o que pressupõe, no entendimento de Bronckart (2006a, 2014) e de Bronckart e Bulea (2011), uma ruptura menos drástica entre o psiquismo primário (biocomportamental) e o pensamento consciente. $\mathrm{Na}$ verdade, a interiorização dos signos faria parte de um processo de continuidade desse psiquismo herdado, ao mesmo tempo que promoveria a sua ruptura na direção sócio-histórica fundadora do humano.

Apesar de colocar a apropriação dos signos no cerne do desenvolvimento humano, Bronckart (2006a) aponta limites da abordagem saussuriana, principalmente quanto ao funcionamento dos textos-discursos nesse processo. Bronckart (2014), por sua vez, postula que a língua, dadas suas condições de funcionamento e de interiorização, não se ancora somente no social, mas também no indivíduo.

Assim, como arremata Bronckart (2006a), manipular os signos enriquece as representações dos sujeitos sobre o mundo e sobre si mesmos, dotando-os de uma capacidade de pensamento e de ação diferentes e superiores à ação prática mais restrita ao seu mundo vivido, de modo que o pensamento consciente é produto da semiotização do psiquismo. Quatro conclusões podem ser tiradas dessa ideia: a constituição do psiquismo humano vem dos outros, do social; o pensamento é orientado pela semântica social que é constitutiva da cultura 
de um grupo; o pensamento, as ações humanas e linguageiras estão organizadas por uma lógica de implicação que remete a intenções e motivos; os signos e os gêneros de texto, que medeiam as práticas de linguagem, são os instrumentos de ação e de (re)estruturação do pensamento consciente (BRONCKART, 1999). Portanto, à medida que interioriza as unidades e a estrutura de uma língua natural, a criança apropria-se de conhecimentos referentes às coordenadas dos mundos representados, num movimento dialético, e adquire um sistema que organiza seu pensamento e sua relação com o mundo, dando origem à racionalidade individual.

\section{Conclusão}

Neste trabalho, procuramos apresentar as contribuições do pensamento saussuriano para a construção do quadro teórico do ISD, por meio da retomada de alguns dos textos mais representativos dessa corrente de estudo da linguagem. Percebemos que, embora Saussure esteja entre os autores basilares da nascente epistemologia interacionista sociodiscursiva, seu protagonismo cresce à medida que se dão a conhecer outras fontes, as quais promovem a releitura e a reativação do interesse pelo mestre genebrino.

Em virtude do foco dosestudos do ISD, as teses saussurianas vêm clarear, ou validar empírica e argumentativamente, o esquema desenvolvimental vygotskiano nos planos filogenético e ontogenético, mas não deixam de chamar atenção conceitos relacionados, por exemplo, à atividade discursiva e sua relação com a língua como sistema social. Mesmo assim, analisar as contribuições de Saussure para o ISD não significa aderir a todas as suas postulações, e são constantes as limitações e ressalvas apontadas, assim como reformulações que alguns dos conceitos têm merecido.

Portanto, o que propõe o ISD é apropriar-se de porções do pensamento saussuriano, mostrando sua validade e atualidade para o quadro epistemológico interdisciplinar em processo constante de construção. $\mathrm{O}$ nosso trabalho, nessa mesma direção, visou a mostrar a dinâmica da assimilação de algumas dessas teses e de suas ressignificações, situando-as nesse escopo teórico. 


\section{REFERÊNCIAS}

BASÍLIO, R.; PEREIRA, R.C.M.; MENEZES, R. de L.C. de. A epistemologia científica que subjaz aos estudos da linguagem no âmbito do Interacionismo Sociodiscursivo. DELTA: Documentação de Estudos em Linguística Teórica e Aplicada, v. 32, n. 2, p. 405-425, maio/ago. 2016. Disponível em: <http://www. scielo.br/pdf/delta/v32n2/1678-460X-delta-32-02-00405.pdf>. Acesso em: 22 dez. 2016.

BOTA, C.; BRONCKART, J-P. Dinâmica e sociabilidade dos fatos de linguagem. In: BRONCKART, J-P.; BULEA, E.; BOTA, C. (orgs.). O projeto de Ferdinand de Saussure. Fortaleza: Parole et Vie, 2014. p. 232-258.

BOUQUET, S. Do pseudossausure aos textos saussurianos originais. In: BRONCKART, J-P.; BULEA, E.; BOTA, C. (orgs.). O projeto de Ferdinand de Saussure. Fortaleza: Parole et Vie, 2014. p. 36-57.

La linguistique générale de Ferdinand de Saussure: textes et retour aux textes. Texto! Textes $\mathcal{E}$ Cultures, v. 4, n 3-4, Não paginado, 1999. Disponível em: <http://www.revue-texto. net/1996-2007/Saussure/Sur_Saussure/Bouquet_Linguist-gen. html>. Acesso em: 12 jun. 2017.

BRONCKART, J-P. A atividade de linguagem frente à LÍNGUA: homenagema Ferdinand deSaussure. In: GUIMARÃES, A.M.M.; MACHADO, A.R.; COUTINHO, A (orgs.). O interaciosnismo sociodiscursivo: questões epistemológicas e metodológicas. CampinasSP: Mercado de Letras, 2007. p. 19-42.

A obra saussuriana e as ciências do homem. In: BRONCKART, J-P.; BULEA, E.; BOTA, C. (orgs.). O projeto de Ferdinand de Saussure. Fortaleza: Parole et Vie, 2014. p. 404-421.

Atividade de linguagem, discurso e desenvolvimento humano. Campinas-SP: Mercado de Letras, 2006a.

BRONCKART, J-P. Atividade de linguagem, textos e discursos: por um interacionismo sócio-discursivo. São Paulo: EDUC, 1999. 
BRONCKART, J-P. Interacionismo sócio-discursivo: uma entrevista com Jean Paul Bronckart. Revista Virtual de Estudos da Linguagem - ReVEL, v. 4, n. 6, p. 1-30, mar. 2006b. Disponível em: $<$ http://www.revel.inf.br/files/entrevistas/revel_6_entrevista_ bronckart_port.pdf>. Acesso em: 8 dez. 2016.

O agir nos discursos: das concepções teóricas às concepções dos trabalhadores. Campinas-SP: Mercado de Letras, 2008.

BRONCKART, J-P.; BULEA, E. Como o psiquismo humano se torna histórico-cultural? As contribuições da análise saussuriana às teses desenvolvimentais de Vigotski. Cadernos Cenpec, n. 1, v. 1, p. 147-166, 2011. Disponível em: <http:// cadernos.cenpec.org.br/cadernos/index.php/cadernos/article/ view/42 $\geq$. Acesso em: 9 dez. 2016.

BRONCKART, J-P.; BULEA, E.; BOTA, C. (orgs.). O projeto de Ferdinand de Saussure. Fortaleza: Parole et Vie, 2014.

CASTRO, M.F.P. de. Ler os manuscritos saussurianos com o Curso de linguística geral. In: FARACO, C.A. (org.). O efeito Saussure: cem anos do Curso de linguística geral. São Paulo: Parábola Editorial, 2016. p. 49-71.

CRUZ, M.A. Por que (não) ler o Curso de linguística geral depois de um século? In: C.A. FARACO, C.A. (org.). O efeito Saussure: cem anos do Curso de linguística geral. São Paulo: Parábola Editorial, 2016. p. 25-48.

FARACO, C.A. Apresentação. In: FARACO, C.A. (org.). O efeito Saussure: cem anos do Curso de linguística geral. São Paulo: Parábola Editorial, 2016. p. 7-24.

GASPARINI, E.N. Sobre a fala no Curso de Linguística Geral: um caminho da liberdade humana?. Revista Prolingua, v. 11, n. 2, p. 61-71, out./dez. 2016. Disponível em: <http://periodicos. ufpb.br/index.php/prolingua/article/view/32223/16770>. Acesso em: 30 dez. 2016. 
MATENCIO, M. de L.M. Textualização, ação e atividade: reflexões sobre a abordagem do Interacionismo Sociodiscursivo. In: GUIMARÃES, A.M.M.; MACHADO, A.R.; COUTINHO, A (orgs.). O interaciosnismo sociodiscursivo: questões epistemológicas e metodológicas. Campinas-SP: Mercado de Letras, 2007. p. 51-63.

RASTIER, F. Saussure e a ciência dos textos. In: BRONCKART, J-P.; BULEA, E.; BOTA, C. (orgs.). O projeto de Ferdinand de Saussure. Fortaleza: Parole et Vie, 2014. p. 378-403.

SAUSSURE, F. de. Curso de linguística geral. 34. ed. São Paulo: Cultrix, 2012.

SILVA, C.L. da C.; TITELLO, D.V. Efeitos do CLG sobre os estudos de texto/discurso: continuidade ou ruptura de fundamentos?. Revista Prolingua, v. 11, n. 2, p 2-12, out./dez. 2016. Disponível em: <http://periodicos.ufpb.br/index.php/ prolingua/article/view/32218/16765>. Acesso em: $30 \mathrm{dez} .2016$.

SILVA, C.U. de C.; SEIDEL, V.F. Noção de valor e/na tradução: um problema de linguística geral?. Revista Prolingua, v. 11, n. 2, p. 80-91, out./dez. 2016. Disponível em: <http://periodicos.ufpb. br/index.php/prolingua/article/view/32248/16824>. Acesso em: 30 dez. 2016.

TRABANT, J. Faut-il défendre Saussure contre ses amateurs? Notes item sur l'étymologie saussurienne. Langages, v. 159, n. 3, p. 111-124, dez. 2005. Disponível em: <https://www.cairn.info/ revue-langages-2005-3-page-111.htm>. Acesso em: 12 jun. 2017.

VICENTE, R.B.; DEFENDI, C.L.; LIMA-HERNANDES, M.C.P. Divergências e contribuições saussurianas à linguística funcionalista. Revista Prolingua, v. 11, n. 2, p. 24-35, out./dez. 2016. Disponível em: <http://periodicos.ufpb.br/index.php/ prolingua/article/view/32220/16767> . Acesso em: $30 \mathrm{dez} .2016$.

VYGOTSKY, L. Pensamento e linguagem. Lisboa: Relógio d'Água Editores, 2007. 


\section{Abstract \\ The point of view of Sociodiscursive Interactionism on Saussure}

A hundred years after the publication of the Course in General Linguistics, linguistics studies have focused attention on the importance and relative relevance of Ferdinand de Saussure's thinking for the consolidation of linguistics as a science and for disciplines in this scientific field. This paper, in this direction, aims at presenting some contributions of Saussure's thought to Sociodiscursive Interactionism, especially in the explanation of human development. It consists of a bibliographical revision of representative texts of Sociodiscursive Interactionism that deal with the resignification and integration of Saussurean theses to this theoretical framework. The texts point out that there is a process of (re) discovering of Saussure's fundamental texts (manuscripts and notes), which, together with those already widely known as the Course in General Linguistics, have provoked reassessments and extensions of some of his theses related to the linguistics of speech, to the language as a social system and, above all, to the linguistic sign, its characteristics and its role in human development in the phylogenetic and ontogenetic planes.

Keywords: Sociodiscursive Interactionism. Saussure. Human development. 